\section{Literature Cited}

(1) Belfort, G. Environ. Sci. Technol. 1979, 13, 939.

(2) Manes, M. In "Activated Carbon Adsorption of Organics from the Aqueous Phase"; Suffet, I. H., McGuire, M. J., Eds.; Ann Arbor Science Publishers: Ann Arbor, MI, 1980; Vol. 1, Chapter 2, p 43.

(3) McGuire, M. J., Suffet, I. H., ref. 2, Chapter 4, p 91.

(4) Zogorski, J. S. Ph.D. Dissertation, Rutgers University, New Brunswick, NJ, 1975.

(5) Keinath, T. M.; Weber, W. J., Jr. J. Water Pollut. Control Fed. $1978,40,741$

(6) Martin, R. J.; Al-Bahrani, K. S. Water Res. 1978, 12, 879.

(7) Weber, W. J., Jr.; Morris, J. C. J. Sanit. Eng. Div., Am. Soc. Civ. Eng. 1964, 90, 79 .
(8) Arbuckle, W. B.; Romagnoli, R. J. Water-1979, CEP Symp. Ser. $1980,76,77$.

(9) Rosene, M. R.; Ozcan, M.; Manes, M. J. Phys. Chem. 1976, 80, 2586 .

(10) Manes, M.; Hofer, L. J. E. J. Phys. Chem 1969, 73, 584 :

(11) Wohleber, D. A.; Manes, M. J. Phys. Chem. 1971, 75, 61.

(12) Rosene, M. R. Ph.D. Dissertation, Kent State University, Kent, $\mathrm{OH}, 1977$.

(13) Keller, C. M.; Snyder, L. R. J. Chromatogr. Sci. 1971, 9, 346

(14) Hansen, C. M. Ind. Eng. Chem. Prod. Res. Dev. 1969, 8, 2.

Received for review September 8, 1980. Accepted March 6, 1981.

\title{
Determination of Formaldehyde in Clean Air
}

\author{
David C. Lowe, * Ulrich Schmidt, and Dleter H. Ehhalt \\ Institut für Chemie 3: Atmosphärische Chemie, Kernforschungsanlage Jülich, GmbH, Postfach 1913, \\ D-5170 Jülich, West Germany
}

\section{Claus G. B. Frischkorn and Hans W. Nürnberg}

Institut für Chemie 4: Angewandte physikalische Chemie, Kernforschungsanlage Jülich, GmbH, Postfach 1913, D-5170 Jülich, West Germany

\begin{abstract}
- A method for determining formaldehyde mixing ratios in the atmosphere is presented. Formaldehyde is stripped from ca. $2 \mathrm{~m}^{3}$ of air into an aqueous 2,4-dinitrophenylhydrazine $(2,4-\mathrm{DNPH})$ solution contained in a high-efficiency, highvolume glass sampler. The resulting reaction product, $\mathrm{CH}_{2} \mathrm{O}-2,4-\mathrm{DNPH}$, is separated and determined by HPLC. Possible interference with the reaction by other components present in air is investigated. The lower detection limit of the technique is $0.01 \mathrm{ppbv}$. At formaldehyde mixing ratios of the order of $0.1 \mathrm{ppbv}$, the precision of the technique is $10 \%$. The sampler is battery powered and portable and can be easily used to sample atmospheric formaldehyde in remote areas. Typical data from a sampling program at the Irish west coast and from Jülich, West Germany, are presented.
\end{abstract}

\section{Introduction}

In the atmosphere formaldehyde $\left(\mathrm{CH}_{2} \mathrm{O}\right)$ is produced as an intermediate product of the oxidation of methane and other hydrocarbons. Model calculations, based on the assumption that methane is the only source gas, predict daytime $\mathrm{CH}_{2} \mathrm{O}$ mixing ratios of $0.1-0.3 \mathrm{ppbv}$ in the lower troposphere (1). This corresponds to concentrations ranging between 130 and $400 \mathrm{ng} / \mathrm{m}^{3}$ (STP) of air. In order to measure such low $\mathrm{CH}_{2} \mathrm{O}$ concentrations, one needs a method of sufficient sensitivity and selectivity. Most of the available chemical techniques for $\mathrm{CH}_{2} \mathrm{O}$ determination have been developed for the measurement of $\mathrm{CH}_{2} \mathrm{O}$ in urban air and lack the sensitivity required to determine $\mathrm{CH}_{2} \mathrm{O}$ in clean air.

A comprehensive list of chemical analysis techniques for $\mathrm{CH}_{2} \mathrm{O}$ is given by Kitchens et al. (2). Optical techniques have also been developed to determine $\mathrm{CH}_{2} \mathrm{O}$ in air $(3,4)$. However, at the present stage of development, optical techniques are only suitable for ground-based measurements made during conditions of good visibility.

This paper describes a chemical technique with sufficient sensitivity and selectivity to measure $\mathrm{CH}_{2} \mathrm{O}$ even in the clean atmosphere. The technique has the advantage of being portable and battery powered. Thus, it can easily be used aboard an aircraft or at remote sampling sites. Background $\mathrm{CH}_{2} \mathrm{O}$ measurements made in the lower troposphere using this technique have been reported by Lowe et al. (5).

\section{Experimental Section}

Because the $\mathrm{CH}_{2} \mathrm{O}$ molecule is very easily trapped on a variety of surfaces, direct detection of nanogram quantities of $\mathrm{CH}_{2} \mathrm{O}$ by standard chromatographic methods is virtually impossible. One way of overcoming this problem is to label the $\mathrm{CH}_{2} \mathrm{O}$ with a compound which is detectable with standard analytical detectors, thus indirectly measuring the original amount of $\mathrm{CH}_{2} \mathrm{O}$ present. Papa and Turner $(6,7)$ have shown that the reaction of 2,4-dinitrophenylhydrazine (2,4-DNPH) with aldehydes to form the corresponding aldehyde 2,4-dinitrophenylhydrazone (aldehyde-2,4-DNPH) with both GC and HPLC as a separation and detection technique is a feasible method for the detection of trace amounts of carbonyl compounds with a lower detection limit for aldehydes of $5 \mathrm{ng}$. $\mathrm{GC}$ analysis requires chemical treatment of the sample, and this appears to have some disadvantages due to the potential contamination from $\mathrm{CH}_{2} \mathrm{O}$ traces in the chemical compounds used.

The 2,4-DNPH technique has been used in food analyses and also for aldehyde determinations in polluted air, for example, in vehicle exhausts $(8,9)$. We chose the 2,4-DNPH technique because its high selectivity, when used in conjunction with HPLC, indicated that it might be a promising method for determining the low formaldehyde concentrations expected in clean air.

A principle requirement for using this method was to design and develop a sampling technique that allowed stripping of the $\mathrm{CH}_{2} \mathrm{O}$ content of $\sim 2 \mathrm{~m}^{3}$ of air into an aqueous solution which could be injected onto the HPLC column. In the following we will describe in detail the various procedures that are involved in sampling and analysis including the modifications of the 2,4-DNPH method that we found to be of essential importance.

Preparation of the DNPH Reagent. A stock solution of 2,4-DNPH reagent is prepared by adding $3 \mathrm{~g}$ of solid recrystalized 2,4-DNPH (Merck, pro analysi, no. 3081) to $10 \mathrm{~mL}$ of high-purity concentrated sulfuric acid (Merck, suprapur, no. 714). This stock solution is further diluted as required; for example, the solution for the air samples is prepared by adding $200 \mu \mathrm{L}$ of the stock solution to $1 \mathrm{~L}$ of water prepared as described below. The resulting solution contains $\sim 60 \mu \mathrm{g}$ of 
2,4-DNPH/mL of solution. The $\mathrm{pH}$ of the solution is 3 .

Obtaining $\mathrm{CH}_{2} \mathrm{O}$-free water for making the sampling solutions presented considerable difficulties. Attempts to free water of $\mathrm{CH}_{2} \mathrm{O}$ by slow distillation over potassium permanganate failed, as did similar attempts with weak hydrogen peroxide solutions. HPLC water (Baker, Analyzed HPLC Reagent, no. 4218) was also found to have an unacceptably high (for this application) formaldehyde blank of $20 \mathrm{ng} / \mathrm{mL}$. The technique finally adopted for use during routine sampling was to treat water by passage through a dual ion exchange high purity water system (Millipore, Milli-Q). After this treatment the $\mathrm{CH}_{2} \mathrm{O}$ concentration of the 2,4-DNPH sampling solutions varies between 0.5 and $5 \mathrm{ng} / \mathrm{mL}$. However, a careful check on the water quality has to be kept because, if the inlet water $\mathrm{CH}_{2} \mathrm{O}$ concentration rises above a threshold value, the Milli-Q system is easily overloaded and the blank $\mathrm{CH}_{2} \mathrm{O}$ concentration of the sampling solutions rises to an unacceptably high value.

Reaction Yield and Sample Stability. The reaction between $\mathrm{CH}_{2} \mathrm{O}$ and 2,4-DNPH is one of addition followed by dehydration and requires an acid catalyst.<smiles></smiles>

The reaction rate increases with decreasing $\mathrm{pH}$. A large excess of the 2,4-DNPH reagent must be present to shift the equilibrium of the reaction in favor of the $\mathrm{CH}_{2} \mathrm{O}-2,4-\mathrm{DNPH}$ product. Typical results for the reaction of $\mathrm{CH}_{2} \mathrm{O}$ with 2,4$\mathrm{DNPH}$ in aqueous solution $(\mathrm{pH} 3)$ at room temperature are shown in Figure 1.

After $1 \mathrm{~h}$ the reaction equilibrium is essentially reached. Once the $\mathrm{CH}_{2} \mathrm{O}-2,4-\mathrm{DNPH}$ product is formed, it is stable in the excess 2,4-DNPH sampling solution for at least 2 weeks when kept well sealed in Pyrex glass bottles stored in a refrigerator at $4{ }^{\circ} \mathrm{C}$. The storage bottles have to be thoroughly rinsed with dilute sulfuric acid and 2,4-DNPH solution before use. Blank 2,4-DNPH solution is always stored in sample bottles and discarded just before filling the bottle with sample solution. New glass bottles render the sampling solution colorless in a few hours, and the characteristic peaks of the 2,4-DNPH reagent and the $\mathrm{CH}_{2} \mathrm{O}-2,4-\mathrm{DNPH}$ product disappear. Polyethylene bottles do not show this effect but show an increase of the $\mathrm{CH}_{2} \mathrm{O}-2,4-\mathrm{DNPH}$ signal with time due to contamination of the sample by formaldehyde originating from the polyethylene. Other plastic containers tested showed similar effects, and metal containers render the solution colorless in a few hours with consequent loss of the characteristic $\mathrm{CH}_{2} \mathrm{O}-2,4-\mathrm{DNPH}$ and 2,4-DNPH peaks. Quartz glass containers have no obvious advantages over Pyrex glass. There-

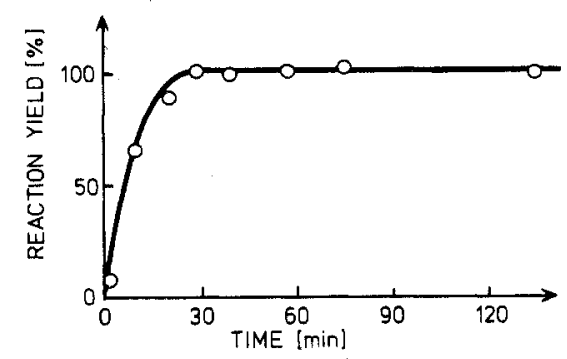

Figure 1. Yield of the reaction of $\mathrm{CH}_{2} \mathrm{O}$ with 2,4-DNPH at room temperature vs. time. fore, for our routine sampling programs we use Pyrex glass bottles conditioned as described above to store both samples and blanks.

Despite these precautions occasionally sample and blank solutions deteriorate in an unpredictable manner after a few days. Storage at $\sim 4^{\circ} \mathrm{C}$ in a refrigerator reduces the deterioration problem considerably. Samples which have deteriorated are easily recongized by a change in color and also the appearance of large peaks which mask the original $\mathrm{CH}_{2} \mathrm{O}-2,4-$ DNPH peak. For most of our routine work, samples are analyzed within a few hours of collection, and the possible deterioration of samples during storage does not pose a problem. However, to prevent the loss of some samples collected in remote areas, we have built a portable HPLC system to enable prompt measurement of samples collected during field campaigns.

Sampling Technique. Most standard air sampling techniques employ impingers or washing flasks at flow rates of a few liters per minute. Zafiriou et al. (10) used a freeze-out technique for $\mathrm{CH}_{2} \mathrm{O}$ collection but report low variable recoveries of $30 \%$.

We have found that impinger flasks and washing flasks are rather inefficient for $\mathrm{CH}_{2} \mathrm{O}$ collection especially at flow rates higher than $10 \mathrm{~L} / \mathrm{min}$. Therefore we have modified a highly efficient high flow rate glass sampler, designed by Münnich and Platt (11), and have used it to sample $\mathrm{CH}_{2} \mathrm{O}$ in the following manner.

The air whose $\mathrm{CH}_{2} \mathrm{O}$ concentration is to be measured is passed at $40 \mathrm{~L} / \mathrm{min}$ through an all-glass sampler containing $\sim 100 \mathrm{~mL}$ of the 2,4-DNPH sampling solution prepared as described above. The sampler used has a volume of 1.5 litre, is $90 \mathrm{~mm}$ in diameter, and is made of Pyrex glass. It contains $1 \mathrm{~L}$ of $4 \times 4 \mathrm{~mm}$ raschig rings tightly packed and held in place by two glass sieve plates (see Figure 2). During sampling the chamber is rotated at $\sim 30 \mathrm{rpm}$, ensuring that all the raschig rings are continuously bathed in the $2,4-\mathrm{DNPH}$ solution. The wet surface area presented to the air flow is very large $\left(1.8 \mathrm{~m}^{2}\right)$, thus increasing the probability of transfer of a $\mathrm{CH}_{2} \mathrm{O}$ molecule across the gas-liquid interface even at relatively high airflow rates. However a minimum volume of solution is required to keep all of the rings wet, and below this volume the efficiency of the sampler decreases rapidly. The minimum load of sampling solution is $40 \mathrm{~mL}$. The efficiency of the sampler for $\mathrm{CH}_{2} \mathrm{O}$ collection was tested for in the following two ways:

(a) An aqueous solution ( $100 \mathrm{~mL}$ ), having a $\mathrm{CH}_{2} \mathrm{O}$ concentration of $\sim 0.5 \mu \mathrm{g} / \mathrm{mL}$, is used to fill a washing flask that is coupled to the inlet of the sampler to be tested. Before a test is begun, two $20-\mathrm{mL}$ aliquots of the $\mathrm{CH}_{2} \mathrm{O}$ solution are taken from the washing flask, and their $\mathrm{CH}_{2} \mathrm{O}$ concentration is determined by using the 2,4-DNPH technique with HPLC.

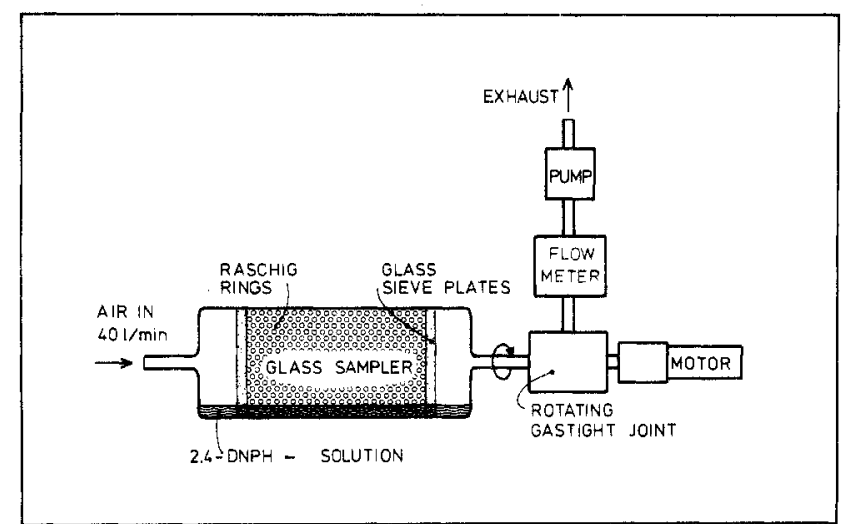

Flgure 2. $\mathrm{CH}_{2} \mathrm{O}$ sampling system (schematic). The sampling chamber is mounted in a frame with the free end supported by a ball-bearing race and rotated by a motor at about $30 \mathrm{rpm}$. The motor coupling is combined with a rotating gas-tight joint. 
$\mathrm{CH}_{2} \mathrm{O}$-free dry nitrogen is then bubbled through the washing flask at the flow rate to be tested, and the sampler collects the outlet vapor and gas from the flask. At the end of the test the concentration of the solution in the washing flask is redetermined by using the 2,4-DNPH technique. From the difference in concentration and the volume of solution in the flask, the amount of $\mathrm{CH}_{2} \mathrm{O}$ released to the sampler can be calculated. The difference between this amout and the amount actually collected by the sampler indicates the efficiency of the sampler.

(b) Two samplers were run in series and the proportion of $\mathrm{CH}_{2} \mathrm{O}$ collected in the second sampler was calculated from the respective amounts in both samplers.

The efficiency of the 1.5-L samplers described above is between 95 and $100 \%$ at airflow rates up to $50 \mathrm{~L} / \mathrm{min}$. The samplers are normally run at $40 \mathrm{~L} / \mathrm{min}$.

The raschig rings should be as tightly packed in the sampler as possible to avoid channeling effects that would change sampling efficiency.

Before its first use a sampler must be conditioned by rinsing with diluted sulfuric acid followed by rinsing with the 2,4DNPH solution. If $2,4-\mathrm{DNPH}$ reagent is put into a newly made sampler, the characteristic yellow color of the reagent quickly disappears, and a chromatogram of the solution indicates that both the 2,4-DNPH and the blank $\mathrm{CH}_{2} \mathrm{O}$ $2,4 \mathrm{NPH}$ have disappeared. The problem appears to be caused by the contact of the 2,4-DNPH solution with new glass surfaces.

Routine sampling for atmospheric $\mathrm{CH}_{2} \mathrm{O}$ is done in the following manner. Immediately before an air sample is taken, the glass sampler is thoroughly rinsed with $1 \mathrm{~L}$ of fresh 2,4DNPH solution prepared by the method described above. Before sampling, a $40-\mathrm{mL}$ aliquot of solution is taken from the sampler to serve as the initial $\mathrm{CH}_{2} \mathrm{O}-2,4-\mathrm{DNPH}$ blank for the air sample. Excess 2,4-DNPH solution is then decanted from the sample until the remaining solution volume in the sampler is $\sim 100 \mathrm{~mL}$ as determined by weight. The sampler is then mounted as shown in Figure 1 and run at $40 \mathrm{~L} / \mathrm{min}$ while rotating at $\sim 30 \mathrm{rpm}$.

If the $\mathrm{CH}_{2} \mathrm{O}$ concentration is expected to be lower than 0.2 ppbv, air is sampled for at least $1 \mathrm{~h}$ for an air sample volume of $\sim 2 \mathrm{~m}^{3}$. For polluted areas, where the $\mathrm{CH}_{2} \mathrm{O}$ concentration is much higher, the air is sampled for a shorter time. After an air sample has been collected, $25 \mathrm{~mL}$ of the 2,4-DNPH sampling solution is decanted off and stored for analysis as the first air sample. A second air sample may be collected by running the sampler for a further period and storing the remaining solution. The volume of the 2,4-DNPH sampling solution after each sampling is determined by weighing the sampler and solution and subtracting the dry weight of the sampler. From the volume of sampling solution used and its $\mathrm{CH}_{2} \mathrm{O}-2,4-\mathrm{DNPH}$ concentration, the mass of $\mathrm{CH}_{2} \mathrm{O}$ collected by the sampler can be calculated. With the additional measurement of the volume of air sampled, the equivalent $\mathrm{CH}_{2} \mathrm{O}$ mixing ratio of the air sample can be calculated.

Analysis by HPLC. A Spectra Physics SP 8000 liquid chromatograph equipped with a SP 8200 UV detector at 254 $\mathrm{nm}$ is used for analysis. The $\mathrm{CH}_{2} \mathrm{O}-2,4-\mathrm{DNPH}$ is separated by using a reversed phase column (Du Pont, Zorbax ODS, 5 $\mu \mathrm{m})$ and a mobile phase of $65 \%$ methanol and $35 \%$ water at a flow rate of $1 \mathrm{~mL} / \mathrm{min}$. The column temperature is $35^{\circ} \mathrm{C}$. Under these conditions the retention time for the $\mathrm{CH}_{2} \mathrm{O}$ $2,4-\mathrm{DNPH}$ product is of the order of $8 \mathrm{~min}$. The samples are injected onto the column by using a relatively large sample loop volume of $300 \mu \mathrm{L}$. Injection of the sample using the large loop was found to be more reproducible than evaporative enrichment and two-phase separation followed by injection with a smaller sample loop. A disadvantage of the larger loop is that the columns deteriorate more rapidly because of the greater reagent load introduced by each injection. Nevertheless, during normal operation the columns gave good results for at least 400 samples before replacement was required.

A typical chromatogram of a sampling solution used to collect an air sample at Jülich is shown in Figure 3. Because of the large excess of 2,4-DNPH used, the chromatogram is dominated by the 2,4-DNPH reagent peaks. Peak 3 is the main 2,4-DNPH peak. Associated with this peak are two other attendant peaks, 4 and 5, whose heights vary in an unpredictable manner with the time since sample collection. In particular, peak 5 increases rapidly with time as the sample deteriorates. Peaks 6 and 7 are the $\mathrm{CH}_{2} \mathrm{O}$ - and $\mathrm{CH}_{3} \mathrm{CHO}-$ 2,4-DNPH peaks, respectively. When the chromatographic parameters listed above are used, peaks 5 and 6 are well resolved and no difficulties are encountered in determining the $\mathrm{CH}_{2} \mathrm{O}$ concentration. However, for samples which have deteriorated because of the decay of the $2,4-\mathrm{DNPH}$ reagent, precise determination of the $\mathrm{CH}_{2} \mathrm{O}-2,4-\mathrm{DNPH}$ is impossible.

For air samples taken in a nonpolluted area, the chromatographic runs were terminated immediately after the elution of the $\mathrm{CH}_{2} \mathrm{O}-2,4-\mathrm{DNPH}$ peaks. However, in a polluted area where higher aldehydes and ketones are likely to be present, the run was left for a longer time to allow the respective aldehyde and ketone 2,4-dinitrophenylhydrazones to be eluted. Acetaldehyde-2,4-DNPH, peak 6, is eluted after $10 \mathrm{~min}$. Propionaldehyde- and acetone-2,4-DNPH are eluted together at $\sim 15 \mathrm{~min}$.

The standard deviation of a series of runs made with a solution of $20 \mathrm{ng}$ of $\mathrm{CH}_{2} \mathrm{O} / \mathrm{mL}$ as $\mathrm{CH}_{2} \mathrm{O}-2,4-\mathrm{DNPH}$ in an aqueous acidic solution of $60 \mu \mathrm{g}$ of $2,4-\mathrm{DNPH} / \mathrm{mL}$ is 0.2 $\mathrm{ng} / \mathrm{mL}$ or $\sim 1 \%$. The lower limit of detection is $0.1 \mathrm{ng} / \mathrm{mL}$.

For a typical clean air sample $\left(2 \mathrm{~m}^{3}\right)$ with a mixing ratio of

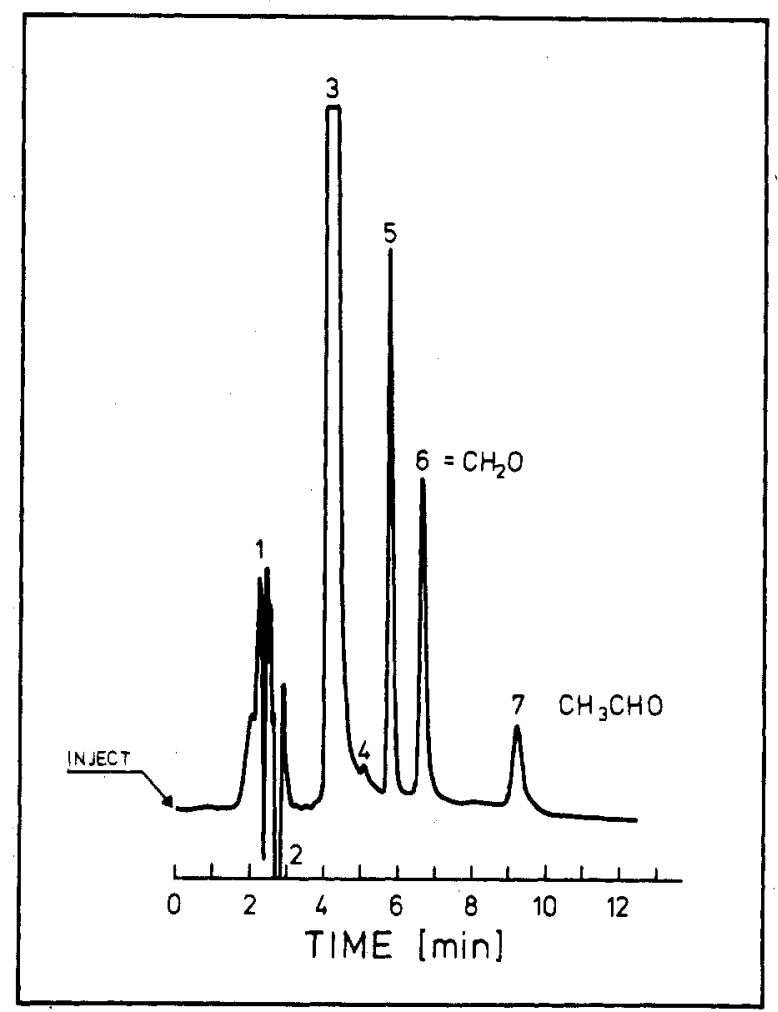

Figure 3. Typical liquid chromatogram of sampling solution used to collect an air sample at the KFA Jülich. Conditions: mobile phase, $65 \%$ $\mathrm{MeOH}, 35 \% \mathrm{H}_{2} \mathrm{O}$; pressure, 72 bar; flowrate, $1 \mathrm{~mL} / \mathrm{min} ; 1$. ion peaks; 2. solvent peak; 3 . main 2,4-DNPH peak; 4,5 , secondary $2,4-D N P H$ peaks; 6, formaldehyde-2,4-DNPH; 7. acetaldehyde-2,4-DNPH. This sample had a $\mathrm{CH}_{2} \mathrm{O}$ concentration of $42 \mathrm{ng} / \mathrm{mL}$ as $\mathrm{CH}_{2} \mathrm{O}-2,4$-dinitrophenylhydrazone. 
$0.2 \mathrm{ppbv}$, the amount of $\mathrm{CH}_{2} \mathrm{O}$ collected by $100 \mathrm{~mL}$ of sampling solution is $540 \mathrm{ng}$. Sampling solutions typically have a blank value of $3.5 \pm 0.2 \mathrm{ng} / \mathrm{mL}$ of $\mathrm{CH}_{2} \mathrm{O}$, and thus the resulting $\mathrm{CH}_{2} \mathrm{O}$ signal is $8.9 \pm 0.2 \mathrm{ng} / \mathrm{mL}$. Since the value of the blank has to be subtracted from this signal, the error increases to $\pm 0.4 \mathrm{ng} / \mathrm{mL}$ or an error of $\sim 10 \%$ of the sample $\mathrm{CH}_{2} \mathrm{O}$ amount. Reducing the blank $\mathrm{CH}_{2} \mathrm{O}$ content would lead to a correspondingly lower error in the measurement of the air sample. However, we have so far not been able to produce systematically sampling solution with a blank concentration of less than $3 \mathrm{ng} / \mathrm{mL}$.

Calibration. Determination of the $\mathrm{CH}_{2} \mathrm{O}-2,4-\mathrm{DNPH}$ concentration of the samples is made by comparison against the peak heights of $\mathrm{CH}_{2} \mathrm{O}-2,4-\mathrm{DNPH}$ standards. These are run frequently during analysis, thus positively identifying the $\mathrm{CH}_{2} \mathrm{O}-2,4-\mathrm{DNPH}$ peaks by retention time and also monitoring any drift in the sensitivity of the HPLC system. The $\mathrm{CH}_{2} \mathrm{O}-2$,4-DNPH standard is made in the following way: reaction of 2,4-DNPH with a diluted aqueous $\mathrm{CH}_{2} \mathrm{O}$ solution derived from a $\mathrm{CH}_{2} \mathrm{O}$ stock solution (Merck, pro analysi, no. $4003)$, the concentration of which was determined by the absolute dimedon method (12) to be $35.8 \pm 0.2 \%$ by weight.

The standard solutions are kept in 1-L Pyrex glass flasks stored in a refrigerator. Standards having $\mathrm{CH}_{2} \mathrm{O}-2,4-\mathrm{DNPH}$ concentrations equivalent to $50 \mathrm{ng}$ of $\mathrm{CH}_{2} \mathrm{O} / \mathrm{mL}$ are generally used. They are renewed every 1-2 months, and a constant check on their integrity is kept by comparison with freshly prepared standard solutions. These always agreed to better than $4 \%$.

Interferences. In polluted air there are many substances which can interfere with the reaction by competively reacting with $\mathrm{CH}_{2} \mathrm{O}$, inhibiting the 2,4-DNPH reagent, or directly reacting with the 2,4-DNPH reagent.

In clean tropospheric air, however, the number of substances likely to interfere with the reaction is limited. We have investigated the effect on the reaction by some compounds which have known reactions with either $\mathrm{CH}_{2} \mathrm{O}$ or 2,4DNPH.

When a stream of $0.1 \%$ ozone in air is passed through a sampler, the 2,4-DNPH solution rapidly turns colorless. To test for interference with the reaction at lower ozone concentrations, we used two identical samplers to sample the same airstream. However, one sampler had small amounts of ozone added to its inlet. The progress of the reaction was monitored in both samplers. No reduction in the yield of the $\mathrm{CH}_{2} \mathrm{O}-2$,4-DNPH product was observed up to the highest ozone mixing ratios-ca. 100 ppbv--employed during these tests. In clean tropospheric air ozone mixing ratios generally do not exceed that level (13), and thus the technique will not be affected for samples collected in this region.

Sulfite reacts quickly with $\mathrm{CH}_{2} \mathrm{O}$ in solution to form a $\mathrm{CH}_{2} \mathrm{O}$ bisulfite adduct. This reaction has been used as the basis of a standard technique for determining the concentration of $\mathrm{CH}_{2} \mathrm{O}$ in solution (14). When $\mathrm{CH}_{2} \mathrm{O}$ is added to a neutral 2,4-DNPH solution containing sodium sulfite, the yield of the $\mathrm{CH}_{2} \mathrm{O}-2,4-\mathrm{DNPH}$ product is reduced. However, when the 2,4-DNPH reagent is made with sulfuric acid (to $\mathrm{pH} 3$ ) as described above, the yield of the $\mathrm{CH}_{2} \mathrm{O}-2,4-\mathrm{DNPH}$ product is $100 \%$ despite added sulfite corresponding to a $\mathrm{SO}_{2}$ mixing ratio in air of 90 ppbv. This is much higher than the $\mathrm{SO}_{2}$ mixing ratios normally observed at Jülich, and hence $\mathrm{SO}_{2}$ will not affect the reaction for samples collected in the clean troposphere.

In marine air chloride could be carried into the sampling solutions because of salt spray. However, no interference with the reaction of $\mathrm{CH}_{2} \mathrm{O}$ with 2,4-DNPH was found when $\mathrm{NaCl}$ was added to the sampling solution in quantities far exceeding those expected to accumulate in the sampler during the sampling of marine air.

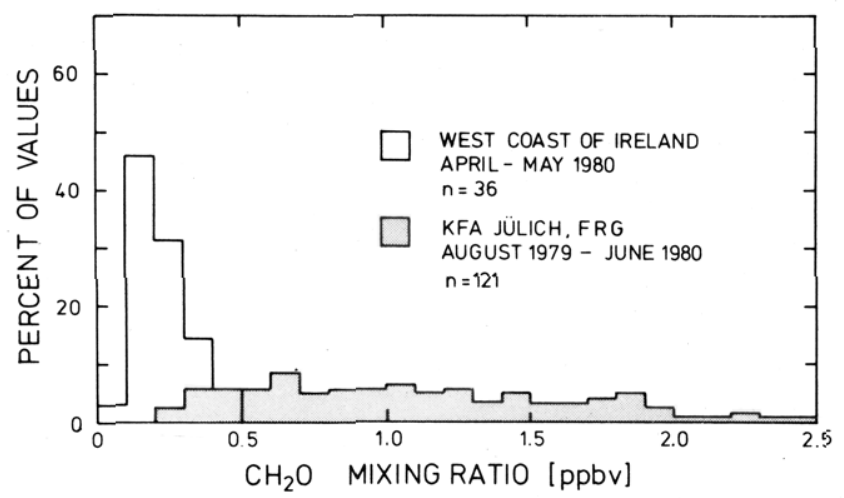

Figure 4. Frequency distribution of $\mathrm{CH}_{2} \mathrm{O}$ mixing ratios observed in slightly polluted continental air (KFA Jülich) and in clean marine air (west coast of Ireland).

It is probable that there are other reactions with $\mathrm{CH}_{2} \mathrm{O}$ in solution and with the 2,4-DNPH reagent which we have not considered. However, the results of $\mathrm{CH}_{2} \mathrm{O}$ measurements made at Jülich, a moderately polluted area, by using the 2,4-DNPH technique are in good agreement with those data obtained by Platt et al. (3) by using a differential optical absorption technique. $\mathrm{CH}_{2} \mathrm{O}$ mixing ratios simultaneously measured by the two techniques typically differed by $\sim 20 \%$. Hence, we believe that the effects of other unconsidered reactions with $\mathrm{CH}_{2} \mathrm{O}$ or the 2,4-DNPH reagent do not significantly interfere with the yield of the $\mathrm{CH}_{2} \mathrm{O}-2,4-\mathrm{DNPH}$ product.

\section{Results}

Atmospheric aerosols contain less than $5 \%$ of the total $\mathrm{CH}_{2} \mathrm{O}$ in air (15). Therefore the air is sampled directly without filters to prevent any loss of $\mathrm{CH}_{2} \mathrm{O}$ during sampling. The results reported here thus make no distinction between gaseous $\mathrm{CH}_{2} \mathrm{O}$ or $\mathrm{CH}_{2} \mathrm{O}$ contained in aerosol particles.

The sampling equipment has been tested near our laboratory at the KFA in Jülich as well as at a remote site in southwestern Ireland. Figure 4 shows a comparison of the frequency distribution of the mixing ratios observed in Ireland and in Jülich. The extremely small spread and the low value of the most frequent mixing ratio observed in Ireland demonstrate that onshore air in western Ireland is relatively uncontaminated. $\mathrm{CH}_{2} \mathrm{O}$ mixing ratios are well inside the range of the values prediced by models of atmospheric chemistry. In contrast the range of mixing ratios observed in Jülich is much larger, reflecting the effect of nearby anthropogenic sources.

During these measurements the technique reported here has been found to be highly practical for sampling atmospheric $\mathrm{CH}_{2} \mathrm{O}$ at remote sites. The lower limit of detection is $0.01 \mathrm{ppbv}$, and, at low $\mathrm{CH}_{2} \mathrm{O}$ mixing ratios of the order of 0.1 ppbv, the precision of the techniques is $\pm 0.01 \mathrm{ppbv}$. The reasonable agreement obtained between the 2,4-DNPH technique and the optical technique, two techniques with completely different detection and calibration principles for $\mathrm{CH}_{2} \mathrm{O}$, indicates that unknown systematic errors or the effect of unknown interference in the 2,4-DNPH technique is likely to be small.

\section{Acknowledgment}

We acknowledge helpful advice given by U. Platt concerning the design of the rotating sampling chambers.

\section{Literature Cited}

(1) Calvert, J. G. In "Proceedings of the NATO Advanced Study Institute on Atmospheric Ozone"; Federal Aviation Agency Report no. FAA-EE-80-20, 1980, pp 153-90.

(2) Kitchens, J. F.; Casner, R. E.; Harward, W. E.; Macri, B. J.; Ed- 
wards, G. S. U.S. Department of Commerce, Report no. PB-256 839, $1976, p 86$.

(3) Platt, U.; Perner, D.; Pätz, H. W. J. Geophys. Res. 1979, 84, 6329-35.

(4) Tuazon, E. C.; Graham, R. A.; Winer, A. M.; Easton, R. R.; Pitts, J. N.; Hanst, P. L. Atmos. Environ. 1978, 12, 865-75.

(5) Lowe, D. C.; Schmidt, U.; Ehhalt, D. H. Geophys. Res. Lett. 1980, 7,825-8.

(6) Papa, L. J.; Turner, L. P. J. Chromatogr. Sci. 1972, 10, 747-50.

(7) Papa, L. J.; Turner, L. P. J. Chromatogr. Sci. 1972, 10, 744-7.

(8) Kuwata, K.; Ueborr, M.; Yamasaki, Y. J. Chromatogr. Sci. 1979, $17,264-8$.

(9) Johnson, L.; Josefssen, B.; Marstorp, P.; Eklund, G. Proceedings of the 10th Annual Symposium on the Analytical Chemistry of Pollutants, Dortmund, West Germany, May 28-30, 1980, to be published as a special issue of Int. J. Environ. Anal. Chem., in press.
(10) Zafiriou, O. C.; Alford, J.; Herrera, M.; Peltzer, E. T,; Gagosian, R. B. Geophys. Res. Lett. 1980, 7, 341-4.

(11) Münnich, K. O.; Platt, U., Institut für Umweltphysik der Universität Heidelberg, Im Neuenheimer Feld 366, D-6900 Heidelberg,

West Germany, personal communication, 1979

(12) Yoe, J. H.; Reid, L. C. Ind. Eng. Chem. 1941, 13, 238-40.

(13) Fabian, P.; Pruchniewicz, P. G. J. Geophys. Res. 1977, 82, 2063-73.

(14) Walker, J. F. "Formaldehyde", 3rd ed.; Robert E. Krieger Publishing Co.: Huntington, NY, 1975; $\mathrm{p} 486$.

(15) Klippel, W.; Warneck, P. Geophys. Res. Lett. 1978, 5, 177-9.

Received for review October 27, 1980. Accepted February 25, 1981. D. C. Lowe thanks the New Zealand Department of Scientific and Industrial Research for support in West Germany in the form of a study award.

\title{
Reactions of Hydrazines with Ozone under Simulated Atmospheric Conditions
}

\author{
Ernesto C. Tuazon, William P. L. Carter, Arthur M. Winer, and James N. Pitts, Jr,* \\ Statewide Air Pollution Research Center, University of California, Riverside, California 92521
}

The gas-phase reactions of ozone with hydrazine $\left(\mathrm{N}_{2} \mathrm{H}_{4}\right)$, monomethylhydrazine (MMH), and unsymmetrical dimethylhydrazine (UDMH) have been studied under simulated atmospheric conditions in a $30000-\mathrm{L}$ outdoor Teflon chamber using in situ long path Fourier transform infrared spectroscopy. The major products are hydrogen peroxide from $\mathrm{N}_{2} \mathrm{H}_{4}+\mathrm{O}_{3}$; methyl hydroperoxide, formaldehyde, methanol, hydrogen peroxide, diazomethane $\left(\mathrm{CH}_{2} \mathrm{~N}_{2}\right)$, and methyldiazene $\left(\mathrm{CH}_{3} \mathrm{~N}=\mathrm{NH}\right)$ from $\mathrm{MMH}+\mathrm{O}_{3}$; and dimethylnitrosamine $\left(\left(\mathrm{CH}_{3}\right)_{2} \mathrm{NNO}\right)$, formaldehyde, hydrogen peroxide, and nitrous acid from UDMH $+\mathrm{O}_{3}$. Diazomethane and methyldiazene react rapidly with excess $\mathrm{O}_{3}$. The results indicate that unsymmetrical disubstituted hydrazines would react very rapidly with ambient levels of ozone in the atmosphere to form nitrosamines and, upon photolysis in sunlight, nitramines, classes of compounds which are known to be carcinogenic. Suggested reaction mechanisms which account for the observed products and their atmospheric implications are discussed.

\section{Introduction}

Until recently the atmospheric chemistry of nitrogencontaining compounds such as amines and hydrazines, which are widely used in industrial and (particularly in the latter case) military applications, has received comparatively little attention. However, within the past several years there have been a number of developments which have brought a greatly increased demand for information concerning the chemical transformations and atmospheric fate of these compounds and their photooxidation products. Among these have been the recognition of the need to further elucidate the role of nitrogenous compounds in the stratosphere and troposphere, discovery of the occurrence of $N$-nitrosamines in the environment, and growing concern regarding the direct and indirect impact of these species on man and his environment.

Hydrazine $\left(\mathrm{N}_{2} \mathrm{H}_{4}\right)$ is used as a source of emergency power for the F-16 fighter plane and in the small thrusters of the space shuttle. Monomethylhydrazine (MMH) is used in the main engine of the space shuttle. A 50-50 mixture of $\mathrm{N}_{2} \mathrm{H}_{4}$ and unsymmetrical dimethylhydrazine (UDMH), known as Aerozine-50, is a fuel for the Titan missile. These uses, along with the attendant transport and storage of large quantities of these compounds, can potentially lead to atmospheric re- leases of hydrazines that can impact on ambient air quality.

Although there have been investigations of the reactions of hydrazines in liquid solutions (1-3), at high temperatures (4-6), and of their heterogeneous oxidation in air at relatively high concentrations (7-11), there have been very few investigations of their reactions with atmospheric species in the ppm concentration range. Since the hydrazines do not photolyze in the solar actinic region $(\lambda>290 \mathrm{~nm})(2)$, their likely reaction pathways in the atmosphere are reaction with ozone $\left(\mathrm{O}_{3}\right)$ and attack by hydroxyl $(\mathrm{OH})$ radical, both of which are generated in photochemical air pollution as well as being present in the unpolluted troposphere. The rate constants for the reactions of $\mathrm{OH}$ with $\mathrm{N}_{2} \mathrm{H}_{4}$ and with $\mathrm{MMH}$ have been measured previously in this laboratory (12). We report here the results of our investigations of the reactions of $\mathrm{O}_{3}$ with $\mathrm{N}_{2} \mathrm{H}_{4}, \mathrm{MMH}$, and UDMH in a large outdoor environmental chamber at concentrations in the ppm range in air. In situ long path Fourier transform infrared spectroscopic techniques were employed to follow reactant consumption and product formation. We believe that these constitute the first set of data which is directly applicable to the assessment of the environmental effects of the release of hydrazines into the atmosphere.

\section{Experimental Section}

Reaction Chamber and FT-IR System. The outdoor reaction chamber employed in this study consists of a 30000-L FEP Teflon bag of triangular cross section held semirigidly by a framework of steel pipes (Figure 1). The outer frame supports a two-section white tarpaulin shield which is opaque to sunlight ( $<0.1 \%$ transmission); it can easily be removed to expose the chamber to solar radiation. Sample injection and gas sampling provisions consisted of a disperser bulb, a disperser tube which runs the length of the chamber, and several glass tubes. Fans attached to the Teflon-coated aluminum end panels provide rapid homogeneous mixing of reactions.

The 10-m basepath multiple-reflection optical system housed in the reaction chamber is based on Horn and $\mathrm{Pi}$ mentel's (13) modification of the White (14) design and is capable of total path lengths in excess of $1 \mathrm{~km}$. Interfaced to this optical system is a rapid-scan Midac interferometer with a maximum resolution capability of $0.06 \mathrm{~cm}^{-1}$. It is equipped with a dual-element $\mathrm{Cu}-\mathrm{Ge}$ and $\mathrm{InSb}$ detector cooled with a 